\title{
The Drosophila segmentation gene runt acts as a position-specific numerator element necessary for the uniform expression of the sex-determining gene Sex-lethal
}

\author{
Joseph B. Duffy ${ }^{1}$ and J. Peter Gergen ${ }^{2}$ \\ ${ }^{1}$ Department of Biochemistry and Molecular Biology, The University of Texas M.D. Anderson Cancer Center, Houston, \\ Texas 77030 USA; $^{2}$ Department of Biochemistry and Cell Biology, State University of New York at Stony Brook, \\ Stony Brook, New York 11794 USA
}

Female development in Drosophila is established through the activation of the X : A target gene Sex-lethal $(S x l)$ by an $X: A$ ratio of 1 . X-linked zygotic genes, termed numerator elements, comprise part of the $X: A$ ratio and are primarily responsible for the activation of $S x I$ in females. We demonstrate that the $X$-linked segmentation gene runt is required for this process and has genetic and molecular properties of a numerator element. Genetically, runt has vital dose-dependent interactions with components of the $X: A$ ratio and alterations in runt activity alter the sexual phenotype of triploid intersexes. Molecularly, loss of runt activity results in a failure to activate appropriately $S x l$ in the central region of female embryos. We also show that $S x l$ activation is influenced by the maternal anterior and terminal pattern-forming genes, bicoid (bcd) and torso (tor). These results indicate that the "uniform" activation of $S x l$ requires input from nonuniformly distributed products. We have demonstrated that runt is one such product and suggest that other genes with nonuniform input exist. runt is distinguished from previously identified regulators of $S x l$ by its nonuniform role and by the absence of an identifiable helix-loop-helix (HLH) motif, indicating that the activation of $S x I$ is not controlled solely by HLH proteins.

[Key Words: Drosophila; segmentation; sex determination; runt; Sex-lethal; numerator; achaete-scute complex; sisterless genes]

Received July 23, 1991; revised version accepted September 12, 1991.

The $\mathrm{X}$ : A ratio determines sexual fate in the fruit fly Drosophila melanogaster by setting the activity of the binary switch gene Sex-lethal $(S x)$ (for review, see Cline 1989; Steinmann-Zwicky et al. 1990). Sxl activity then coordinately regulates both sexual determination and dosage compensation to establish sexual dimorphism in all somatic cells (Cline 1983). The regulation of $S_{x l}$ activity involves two major steps: initiation and maintenance (Sanchez and Nothiger 1983; Cline 1984; Maine et al. 1985). Initiation involves the response of $S x l$ to the $\mathrm{X}$ : A ratio. This leads to either the on/female mode $(X: A=1)$ or the off/male mode $(X: A=0.5)$ (Cline 1978). After this decision has been made, maintenance of either mode of $S_{x l} l$ activity ensures the stable commitment of a cell to its initial sexual choice. This occurs post-transcriptionally through the differential splicing of transcripts from a constitutive promoter (Bell et al. 1988; Salz et al. 1989|. The on mode in females is maintained through a positive autoregulatory loop, which involves the ability of the $S x l$ protein to regulate its own splicing
(Bell et al. 1991). However, Sxl protein must be present initially in females and not in males to start such a loop and maintain the female versus male mode. Thus, whereas the autoregulatory loop explains the maintenance of $S x l$ activity in females, it does not answer the question of how the initiation of $S x l$ activity occurs only in females.

Two lines of evidence suggest that the initiation step of $S x l$ occurs at the level of transcription. First, there are embryonic-specific transcripts of $S x l$, which appear to utilize an embryonic-specific promoter and not the constitutive promoter (Salz et al. 1989; L. Keyes et al., in prep, cited in Erickson and Cline 1991). Second, factors involved in the initiation of $S x l$ have DNA-binding and dimerization motifs indicative of transcriptional regulators (Villares and Cabrera 1987; Caudy et al. 1988; Cronmiller et al. 1988; Murre et al. 1989a,b; Parkhurst et al. 1990/. Thus, the X : A ratio appears to set $S x l$ activity through the transcriptional regulation of the embryonicspecific promoter. In the on mode $(\mathrm{X}: \mathrm{A}=1) \mathrm{Sxl}$ tran- 
scription is initiated from this promoter in all somatic cells, thereby establishing the female pathway of development. In the off mode (X:A $=0.5) S x 1$ transcription fails to be initiated from this promoter, resulting in the male (default) pathway. After the $\mathrm{X}$ : A ratio has been "read," Sxl transcription switches to the constitutive promoter and positive autoregulation maintains the female versus male mode.

Determining how Drosophila reads the $\mathrm{X}$ : A ratio in molecular terms is then a question of understanding the transcriptional regulation of the embryonic promoter of Sxl. The recent identification of components of the $\mathrm{X}: \mathrm{A}$ ratio has provided insight into this process. Numerator elements are $\mathrm{X}$-linked zygotic components that provide positive (feminizing) input into the $\mathrm{X}$ : A ratio and act in a dose-dependent fashion (Bridges 1921, 1925; Cline 1988). Two loci that act as numerator elements, sisterless- $a($ sis- $a)$ and sisterless- $b($ sis- $b)$, have been identified (Cline 1986, 1988). sis-b has been characterized at the molecular level and corresponds to the $\mathrm{T} 4$ transcription unit of the Achaete-scute complex $(A S-C)$ (Cline 1988; Torres and Sanchez 1989; Parkhurst et al. 1990; Erickson and Cline 1991). In addition to its role as sis-b, T4 also functions as scute-alpha of the $A S-C$ during neural development (for review, see Ghysen and DamblyChaudiere 1988). T4 encodes a protein with the basic helix-loop-helix (bHLH) DNA binding (b) and dimerization motif (HLH) (Murre et al. 1989a). This motif, the lack of $S x l$ expression in the absence of $s i s-b$ activity, and the ectopic expression of $S \mathrm{xl}$ in response to misexpression of $s i s-b$ all strongly suggest that $s i s-b$ plays a critical role in the initiation of $S \times l$ transcription in female embryos (Parkhurst et al 1990; Bopp et al. 1991). The initiation of $S x l$ transcription also involves maternal as well as zygotic input. The gene daughterless $(d a)$ encodes a maternally expressed bHLH protein that cooperates with $s i s-b$ and sis- $a$ in the initiation of $S \times 1$ activity /Cline 1986, 1988; Murre et al. 1989a; Parkhurst et al. 1990; Bopp et al. 1991).

Denominator elements are hypothetical autosomal components against which numerator elements are measured (Bridges 1921, 1925; Cline 1988). Random autosomal-binding sites could limit the access of numerator elements to the $S \times l$ promoter to provide such negative input (Parkhurst et al. 1990; Erickson and Cline 1991). A second possibility is the use of inhibitory gene products (Parkhurst et al. 1990; Erickson and Cline 1991). The bHLH protein hairy $(h)$ and the HLH protein extramacrochaetae (emc) inhibit the function of scute-alpha (T4) and achaete (T5) of the $A S$ - $C$ during bristle formation (Botas et al. 1982; Moscoso del Prado and Garcia-Bellido 1984a,b; Garcia-Alonso and Garcia-Bellido 1988; Rushlow et al. 1989; Ellis et al. 1990; Garrell and Modolell 1990; Cubas et al. 1991; Skeath and Carroll 1991). Consistent with a possible inhibitory role, emc and $h$ are expressed at the time of $S x l$ initiation; the embryonic $S x l$ RNAs are detected from $\sim 2-4 \mathrm{hr}$ of development and $e m c$ and $h$ expression are also detected at this time (Ingham et al. 1985; Salz et al. 1989; Ellis et al. 1990; Garrell and Modolell 1990). Furthermore, misexpression of $h$ prior to cellular blastoderm has been shown to inhibit the ability of $s i s-b$ to activate $S x 1$ expression (Parkhurst et al. 1990). A third possibility is that denominator elements, as such, do not exist. Cooperative interactions and the possible autoregulation of sis genes, coupled with the twofold difference in target gene $(S x l)$ dose, could amplify a twofold difference in sis gene dose in females to protein concentrations sufficient to initiate the expression of $S x l$ (Parkhurst et al. 1990; Erickson and Cline 1991). Although no denominator elements have been identified, transduction of the $\mathrm{X}: \mathrm{A}$ ratio may utilize all of these molecular mechanisms to distinguish between female $(\mathrm{X}: \mathrm{A}=1)$ and male $(\mathrm{X}: \mathrm{A}=0.5)$ chromosomal environments.

In this paper we present the identification and characterization of a unique component involved in the initiation of $S x l$ activity. We prove, genetically and molecularly, that in addition to its role in segmentation, the runt gene interacts with sis- $b$ to activate $S x l$ expression. We demonstrate that runt has other properties consistent with numerator elements and that this role occurs before segmentation, and establish that runt provides nonuniform input required for the "uniform" activation of $S x l$. We also indicate that the maternal anterior and terminal organizing systems control inputs other than runt that are involved in generating the uniform pattern of $S x l$ expression in females. M. Torres and L. Sanchez (pers. comm.) have also demonstrated that runt activity is required for the initial step in the activation of Sxl.

\section{Results}

$A$ vital interaction between the segmentation gene runt and the T4 gene of the AS-C

A vital interaction between the $\mathrm{X}$-linked gene runt (19E2) and the $\mathrm{X}$ chromosome region $1 \mathrm{~A} 1 ; 1 \mathrm{~B} 5-6$ was discovered during a screen for maternal dose-dependent enhancers of a dominant runt segmentation phenotype (this screen will be described elsewhere). During this screen we discovered that the viability of females transheterozygous for a deficiency of this region [Df(1)260-1] and a null allele of runt $\left(\right.$ run $\left.^{L B 5}\right)$ was dramatically reduced (Table 1). A deficiency that removes most of this region $\left[\mathrm{Df}(1) s c^{19}\right]$ also interacted with this and other runt alleles (Table 1; unpubl.). This indicated that the interaction was not the result of second-site mutations on either the Df(1)260-1 or the run ${ }^{L B 5}$ chromosomes. A series of deficiencies subdividing this region was tested to map the gene(s) responsible for this interaction with runt. Because dose-dependent interactions are often sensitive to genetic background, all deficiencies were outcrossed once to a stock carrying an isogenized yw $\mathrm{X}$ chromosome. As a further control the viability of females heterozygous for each of the deficiencies alone was measured. The results in Table 1 suggest that the interaction maps to the region containing the T4 transcription unit of the AS-C. Results obtained with the T4 nonsense mutation $s c^{10-1}$ and the T4 temperature-sensitive mutation $s c^{3-1}$ confirmed this (Table 1). Similar results were ob- 
Table 1. Mapping a genetic interaction between runt and the AS-C

\begin{tabular}{|c|c|c|c|c|c|}
\hline \multirow{2}{*}{$\begin{array}{l}\text { Maternal } \\
\text { genotype }\end{array}$} & \multirow{2}{*}{$\begin{array}{l}\text { Genes } \\
\text { deleted }\end{array}$} & \multicolumn{4}{|c|}{ Percent viability ${ }^{a}$} \\
\hline & & $y w$ & $\operatorname{run}^{L B 5}$ & $\operatorname{run}^{X A 06}$ & $\operatorname{run}^{A A 33}$ \\
\hline Df $260-1 /+$ & $\mathrm{Tla}, \mathrm{T} 3, \mathrm{~T} 4, \mathrm{~T} 5$ & $\begin{array}{c}73 \\
(260 / 357)\end{array}$ & $\begin{array}{c}26 \\
(153 / 596)\end{array}$ & $\mathrm{ND}^{\mathrm{b}}$ & $\mathrm{ND}^{\mathrm{b}}$ \\
\hline Df $s c^{19} /+$ & $\mathrm{T} 3, \mathrm{~T} 4, \mathrm{~T} 5$ & $\begin{array}{c}45 \\
(164 / 367)\end{array}$ & $\begin{array}{c}12 \\
(67 / 556)\end{array}$ & $\begin{array}{c}2 \\
(3 / 127)\end{array}$ & $\begin{array}{c}5 \\
(28 / 603)\end{array}$ \\
\hline Df $s c^{2} /+$ & Tla & $\begin{array}{c}105 \\
(318 / 303)\end{array}$ & $\begin{array}{c}99 \\
(342 / 345)\end{array}$ & $\begin{array}{c}116 \\
(229 / 198)\end{array}$ & $\begin{array}{c}102 \\
(258 / 252)\end{array}$ \\
\hline In $y^{3 P L}-S C^{8 R} /+$ & T5 & $\begin{array}{c}100 \\
(269 / 268)\end{array}$ & $\begin{array}{c}104 \\
(309 / 298)\end{array}$ & $\begin{array}{c}109 \\
(35 / 32)\end{array}$ & $\begin{array}{c}100 \\
(289 / 290)\end{array}$ \\
\hline In $s c^{8 L}-s c^{4 R} /+$ & $\mathrm{T} 4$ & $\begin{array}{c}100 \\
\{85 / 86\}\end{array}$ & $\begin{array}{c}20 \\
(23 / 114)\end{array}$ & ND & ND \\
\hline$s c^{10-1} /+$ & $\mathrm{T} 4, \mathrm{~T} 5$ & $\begin{array}{c}85 \\
(313 / 368)\end{array}$ & $\begin{array}{c}36 \\
(146 / 404)\end{array}$ & $\begin{array}{c}21 \\
(43 / 208)\end{array}$ & $\begin{array}{c}18 \\
(85 / 482)\end{array}$ \\
\hline$s c^{3-1} /+\left(18^{\circ} \mathrm{C}\right)$ & T4 (permissive) & $\begin{array}{c}105 \\
(159 / 151)\end{array}$ & $\begin{array}{c}122 \\
(178 / 146)\end{array}$ & $\begin{array}{c}74 \\
(132 / 178)\end{array}$ & $\begin{array}{c}131 \\
(210 / 160)\end{array}$ \\
\hline$s c^{3-1} /+\left(25^{\circ} \mathrm{C}\right)$ & $\mathrm{T} 4$ & $\begin{array}{c}109 \\
(237 / 217)\end{array}$ & $\begin{array}{c}67 \\
(231 / 345)\end{array}$ & $\begin{array}{c}42 \\
(95 / 227)\end{array}$ & $\begin{array}{c}71 \\
(214 / 303)\end{array}$ \\
\hline$s c^{3-1} /+\left(30^{\circ} \mathrm{C}\right)$ & T4 (restrictive) & $\begin{array}{c}\mathbf{5 1} \\
(38 / 75)\end{array}$ & $\begin{array}{c}4 \\
(6 / 135)\end{array}$ & $\begin{array}{c}10 \\
(8 / 83)\end{array}$ & $\begin{array}{c}15 \\
(23 / 154)\end{array}$ \\
\hline
\end{tabular}

${ }^{a}$ Females carrying the indicated $X$ chromosome deficiency or point mutation over a wild-type X chromosome $(+)$ were mated to males carrying one of the indicated paternal $\mathrm{X}$ chromosomes $\left(y w\right.$,run ${ }^{L B 5}$, run ${ }^{X A 06}$, run $\left.{ }^{A A 33}\right)$. Males carrying a runt allele also carried a $\mathrm{Y}$ chromosome duplication for runt. The percent viability was calculated by dividing the number of female progeny trans-heterozygous for the indicated maternal deficiency or point mutation and the indicated paternal $\mathrm{X}$ ( $\mathrm{yw}$ or runt allele) by the number of female progeny trans-heterozygous for the maternal wild-type $\mathrm{X}$ chromosome $(+)$ and the indicated paternal $\mathrm{X}$ chromosome (yw or runt allele). The numbers of progeny scored for each of these classes are indicated in parentheses. In the absence of an interaction the viability of females trans-heterozygous for a runt allele and a deficiency (or point mutation) should be the same as that of females trans-heterozygous for the yw chromosome and the corresponding deficiency (or point mutation).

b(ND) Not done.

tained with two runt null mutations: $\operatorname{run}^{L B 5}$ (a $5-\mathrm{kb}$ deletion that removes the runt transcription unit) and run $^{X A 06}$ (an EMS-induced mutation). In addition, other runt alleles interact, but there does not appear to be a simple correlation between the segmentation phenotypes of these runt alleles and their ability to interact with T4. For example, the allele $\operatorname{run}^{A A 33}$ has a weak segmentation phenotype (Gergen and Weischaus 1986) but a strong interaction with $\mathrm{T} 4$ (Table 1). These results demonstrate that the T4 transcript of the $A S-C$ and the segmentation gene runt have a vital interaction in a trans-heterozygous situation. A recombination experiment indicated that $\mathrm{Df}(1) s c^{19}$ and run $^{L B 5}$ also interacted when heterozygous in a cis configuration (see Table 2).

Proof that this interaction involved T4 and runt was provided by testing transposons or chromosomal dupli-

Table 2. Effect of additional runt or AS-C DNA on their haplo-insufficient interaction

\begin{tabular}{|c|c|c|c|c|c|c|c|}
\hline \multirow[b]{2}{*}{ Maternal genotype ${ }^{a}$} & \multicolumn{7}{|c|}{ Percent viability ${ }^{\mathrm{b}, \mathrm{c}}$} \\
\hline & $y w$ & $\mathrm{Tp} r u n t^{O P 1}$ & $\mathrm{Tp}$ runt ${ }^{O P 2}$ & Tp runt ${ }^{C D 2}$ & Tp runt/lac & Dp $s c^{19}$ & $\mathrm{Tp} \mathrm{T} 4$ \\
\hline$s c^{19} \operatorname{run}^{L B 5} / \mathrm{FM} 7(2)$ & $\begin{array}{c}28 \\
(140 / 501)\end{array}$ & $\begin{array}{c}92 \\
(516 / 558)\end{array}$ & $\begin{array}{c}\mathbf{8 2} \\
\langle 150 / 183)\end{array}$ & $\begin{array}{c}\mathbf{4 6} \\
(157 / 342)\end{array}$ & $\begin{array}{c}15 \\
(44 / 285)\end{array}$ & $\begin{array}{c}120 \\
(376 / 314)\end{array}$ & $\begin{array}{c}99 \\
(101 / 102)\end{array}$ \\
\hline$s c^{19}+/ F M 7(6)$ & $\begin{array}{c}89 \\
(100 / 112)\end{array}$ & $\begin{array}{c}106 \\
(699 / 600)\end{array}$ & $\begin{array}{c}87 \\
(177 / 203)\end{array}$ & ND & $\begin{array}{c}67 \\
(119 / 178)\end{array}$ & ND & $\begin{array}{c}129 \\
(48 / 39)\end{array}$ \\
\hline$+\operatorname{run}^{L B 5} / \mathrm{FM} 7$ & $\begin{array}{c}106 \\
(416 / 394)\end{array}$ & $\begin{array}{c}141 \\
(76 / 54)\end{array}$ & ND & ND & ND & ND & ND \\
\hline
\end{tabular}

${ }^{a}$ Numbers in parentheses indicate different recombinant lines.

bFemales of the indicated maternal genotype were mated to either control $(y w)$ males or males carrying the indicated transposon or duplication (for details, see Materials and methods). The percent viability was calculated by dividing the number of female progeny carrying the maternal recombinant $\mathrm{X}$ chromosome and the indicated paternal chromosome ( $y w$, a transposon, or the duplication) by the number of females carrying the maternal balancer $\mathrm{X}$ chromosome and the indicated paternal chromosome / yw, a transposon, or the duplication). The actual number of progeny scored for each class is indicated in parenthesis.

'(ND) Not done. 
cations with different levels of runt or T4 activity for their ability to suppress the reduction of viability seen in the $\mathrm{Df}(1) s c^{19}{ }^{1} \operatorname{run}^{L B 5}\left(\mathrm{~T}_{4}^{-}\right.$, run $\left.^{-}\right)$recombinant line (Table 2). One copy of two different insertions of a runt transposon, OP1 and OP2, (for details on these transposons, see Gergen and Butler 1988) each suppressed the runt-T4 interaction (Table 2). The runt transposon CD2 has less upstream DNA than OP1 or OP2 and is less effective than OP1 or OP2 in suppressing the runt-T4 interaction (Table 2). We also tested a transposon carrying the same amount of runt upstream DNA as OP1 but fused to the $\beta$-galactosidase-coding region instead of the runt-coding region (B. Butler et al., in prep.). This transposon does not suppress the runt-T4 interaction (Table 2). These results prove that the interaction is dependent on runt activity. A duplication of most of the AS-C $\left[\mathrm{Dp}(1 ; 2) s \mathrm{c}^{19}\right]$, as well as a transposon containing just $\mathrm{T} 4$ also rescued the runt-T4 interaction (Table 2) (Erickson and Cline 1991). These results confirm that the vital interaction is with the T4 transcription unit.

Dose-dependent interactions have been mapped to the $A S-C$ previously (Botas 1982; Moscoso del Prado and Garcia-Bellido 1984a,b; Cline 1988; Dambly-Chaudiere et al. 1988; Garcia-Alonso and Garcia-Bellido 1988). This genetically and molecularly complex region contains four different transcription units (T1a, T3, T4, and T5) that encode related proteins (for review, see Ghysen and Dambly-Chaudiere 1988; Cline 1989). We have shown that $\mathrm{T} 4$ and runt have a vital interaction. To determine whether T4 is the only transcription unit of the $A S-C$ to have a vital interaction with runt, the viability of females triple heterozygous for mutations in $\mathrm{T} 1 \mathrm{a}, \mathrm{T} 5$, and runt was tested. Females of this genotype did not show any reduction in viability (data not shown). In addition, rescued females carrying the $\mathrm{Df}(1) s c^{19}$, $\operatorname{run}^{L B 5}\left(\mathrm{~T}^{-}{ }^{-}\right.$, run $^{-}$| recombinant chromosome and the $\mathrm{T} 4$ transposon are still heterozygous for $\mathrm{T} 3, \mathrm{~T} 5$, and runt. These results prove that T4 is the only member of the $A S-C$ that has a vital interaction with runt.

The runt-T4 interaction involves the sis-b function of $T 4$

The AS-C T4 transcription unit has two separable roles involving different developmental pathways. Early in development $\mathrm{T} 4$ functions as sis- $b$ in the process of sex determination/dosage compensation /Cline 1988; Torres and Sanchez 1989; Parkhurst et al. 1990; Erickson and Cline 1991). At later stages T4 functions as scute-alpha in the development of the nervous system (for review, see Ghysen and Dambly-Chaudiere 1988). Dose-dependent interactions for both functions of $\mathrm{T} 4$ have been documented. As sis-b, T4 interacts with the genes $S \times l, d a$, and sis- $a$ to initiate the female mode of development (Cline 1988). As scute-alpha, T4 has been shown to interact with the genes $h$, emc, and $d a$ in the formation of the peripheral nervous system (bristles) (Botas 1982; Moscoso del Prado and Garcia-Bellido 1984a,b; DamblyChaudiere et al. 1988; Garcia-Alonso and Garcia-Bellido 1988; Cubas et al. 1991; Skeath and Carroll 1991).
To determine whether the runt-T4 interaction involved the scute-alpha function, surviving females trans-heterozygous for $s c^{10-1}$ and run $^{L B 5}$ and for Df(1)sc $c^{19}$ and run $^{L B 5}$ were scored for bristle defects (see Materials and methods). No major effects on the pattern of head or thoracic bristles was observed. This provided preliminary evidence that the runt-T4 interaction did not involve the scute-alpha function of $\mathrm{T} 4$.

As sis-b, T4 is a component of the $\mathrm{X}$ : A ratio and is required in females for the initiation of $\mathrm{Sxl}$ expression (Cline 1988; Torres and Sanchez 1989; Parkhurst et al. 1990; Erickson and Cline 1991; Bopp et al. 1991). A failure to activate $S x l$ expression in females results in lethality due to improper dosage compensation (Lucchesi and Skripsky 1981; Gergen 1987). The viability of females heterozygous for both runt and T4 could be reduced because they fail to properly initiate $S x l$ expression. Support for this is seen by the occasional masculinization of surviving females trans-heterozygous for T4 and runt. If this is true then the reduction in viability of

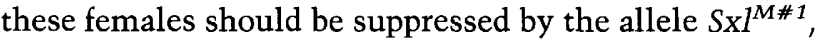
which causes constitutive expression of $S x l$ independent of the X : A ratio (Cline 1978). The results in Table 3 show that when the $S x l^{M \# 1}$ allele is present on the $\mathrm{Df}(1) s c^{19}$ chromosome, the reduction in viability of females that are trans-heterozygous for $\mathrm{Df}(1) s \mathrm{c}^{19}$ and run $^{L B 5}$ or run rA33 $^{A A}$ suppressed $(12 \%$ increased to $111 \%$ and $15 \%$ increased to $125 \%)$. Similar results were obtained with different recombinant lines (Table 3). This

Table 3. $\mathrm{Sxl}^{\mathrm{M \# 1}}$ rescues the interaction between runt and T4

\begin{tabular}{lccc}
\hline & \multicolumn{3}{c}{ Percent viability $^{\mathrm{b}}$} \\
\cline { 2 - 4 } Maternal genotype $^{\mathrm{a}}$ & $y w$ & run $^{L B 5}$ & run $^{A A 33}$ \\
\hline$s c^{19}+/ F M 7(6)$ & $\mathbf{7 8}$ & $\mathbf{1 2}$ & $\mathbf{1 5}$ \\
& $(118 / 115)$ & $(21 / 177)$ & $(33 / 216)$ \\
$s c^{19}+/ F M 7(7)$ & $\mathbf{7 4}$ & $\mathbf{1}$ & $\mathbf{1 2}$ \\
& $(78 / 106)$ & $(1 / 108)$ & $(6 / 50)$ \\
$s c^{19} S x I^{M \# 1} / \mathrm{FM} 7(\mathrm{a})$ & $\mathbf{1 0 3}$ & $\mathbf{1 1 1}$ & $\mathbf{1 2 5}$ \\
& $(203 / 197)$ & $(\mathbf{1 8 8 / 1 6 9 )}$ & $(141 / 113)$ \\
$s c^{19} S \mathrm{~S} l^{M \# 1} / \mathrm{FM} 7(\mathrm{c})$ & $\mathbf{1 4 0}$ & $\mathbf{1 6 9}$ & $\mathbf{1 6 6}$ \\
& $(172 / 123)$ & $(193 / 114)$ & $(146 / 88)$ \\
$+S x l^{M \# 1} / \mathrm{FM} 7(\mathrm{~b})$ & $\mathbf{1 2 5}$ & $\mathbf{1 2 1}$ & $\mathbf{1 1 0}$ \\
& $(223 / 178)$ & $(211 / 175)$ & $(56 / 51)$ \\
$+S x I^{M \# 1} / \mathrm{FM} 7(\mathrm{e})$ & $\mathbf{1 2 1}$ & $\mathbf{9 9}$ & $\mathbf{1 3 2}$ \\
& $(169 / 140)$ & $(130 / 131)$ & $(174 / 132)$ \\
\end{tabular}

${ }^{a}$ Numbers and letters in parentheses indicate different recombinant lines.

${ }^{b}$ Females of the indicated maternal genotype were mated to control $(y w)$ males or males carrying either the $\operatorname{run}^{L B 5}$ or run ${ }^{A A 33}$ alleles. The percent viability was calculated by dividing the number of female progeny trans-heterozygous for the indicated maternal recombinant $X$ chromosome $\left[s c^{19}+\text {, or } s c^{19} S x\right]^{M \# 1}$, or $\left.+S x l^{M \# 1}\right)$ and the indicated paternal $X$ chromosome $(y w$, run $^{L B 5}$, run ${ }^{A A 33}$ ) by the number of female progeny trans-heterozygous for the maternal balancer $\mathrm{X}$ chromosome and the indicated paternal $X$ chromosome $\left(y w, \operatorname{run}^{L B 5}\right.$, run $\left.^{A A 33}\right)$. The actual number of progeny scored for each class is indicated in parentheses. 
result indicates that the runt-T4 interaction involves the sis- $b$ function of $\mathrm{T} 4$, which provides the first genetic evidence implicating a segmentation gene (runt) in the normal regulation of $S x l$ and consequently in sex determination/dosage compensation. This is also the first example of a non-bHLH protein involved in this process.

\section{runt has additional genetic properties indicative of a numerator}

Numerator elements have been predicted to have certain properties as components of the $\mathrm{X}$ : A signal /Cline 1988). They should be X-linked and exhibit zygotic dosedependent interactions. Increases in their activity should feminize triploid intersexes, while decreases should masculinize triploid intersexes. In addition, they should have some ability to compensate for each other and to induce male lethality. runt is an X-linked gene and exhibits a zygotic dose-dependent interaction with sis- $b$. runt also has interactions with $S x I$ and sis-a (Table 4; $M$. Torres and L. Sanchez, pers. comm.). The viability of females trans-heterozygous for runt and $S x 1$ or sis-a is reduced to $\sim 50 \%$. These data were a preliminary suggestion that runt might act as a numerator element. To determine whether runt has other genetic properties indicative of numerator elements we tested runt for effects on triploid intersexes and for the ability to compensate for a loss in sis- $b$ activity.

Ambiguous sexual development can be created with triploid intersexes (an X : A ratio of 0.67; Bridges 1921). An increase in the dose of elements of the female signal (numerator elements) feminizes triploid intersexes, whereas a decrease in the dose masculinizes triploid intersexes (Cline 1986, 1988). To determine whether runt is a component of the female signal we analyzed the effects of increased and decreased runt activity in trip-

Table 4. runt interacts with $\mathrm{Sxl}$ and sis-a

\begin{tabular}{cccc}
\hline & \multicolumn{3}{c}{ Percent viability $^{\mathrm{a}}$} \\
\cline { 2 - 4 } Maternal genotype & $y w$ & $S x f^{f \# 1}$ & $\begin{array}{l}\text { Df(1)N71 } \\
\left(\text { sis- } a^{-}\right)\end{array}$ \\
\hline Df $y^{3 p l}-s c^{8 r} / \mathrm{FM} 7$ & $\mathbf{1 4 1}$ & $\mathbf{1 0 5}$ & $\mathrm{ND}^{\mathrm{b}}$ \\
$\left(s i s-b^{+}\right)$ & $(165 / 117)$ & $(256 / 243)$ & \\
Df $s c^{19} / \mathrm{FM} 7$ & $\mathbf{3 8}$ & $\mathbf{0}$ & $\mathrm{ND}^{\mathrm{b}}$ \\
$\left(s i s-b^{-}\right)$ & $(50 / 130)$ & $(0 / 194)$ & \\
run $^{\text {LB5 }} / \mathrm{FM} 7$ & $\mathbf{1 0 6}$ & $\mathbf{5 0}$ & $\mathbf{5 5}$ \\
$\left(\mathrm{run}^{-}\right)$ & $(416 / 391)$ & $(206 / 416)$ & $(286 / 519)$ \\
\hline
\end{tabular}

${ }^{a}$ Females of the indicated maternal genotype were mated to control $(y w)$ males or to males carrying either $S x l^{f \# 1}$ or $D F(1) N 71$. The percent viability was calculated by dividing the number of female progeny trans-heterozygous for the indicated maternal $\mathrm{X}$ chromosome $\left[\mathrm{Df}(1) y^{3 p I_{-}} s c^{8 r}, \mathrm{Df}(1) s c^{19}\right.$, and $\left.\operatorname{run}^{L B 5}\right)$ and the indicated paternal $X$ chromosome $\left(y w, S_{x}\right\}^{f \# 1}$, or N71) by the number of female progeny trans-heterozygous for the maternal balancer $\mathrm{X}$ chromosome and the indicated paternal $\mathrm{X}$ chromosome $\left\{y w, S x f^{\# 1}\right.$, or N71). The actual number of progeny scored for each class is indicated in parentheses.

b(ND) Not done. loid intersexes. To minimize effects due to genetic background these experiments were done in the absence of balancer chromosomes. Increasing runt dose with the runt transposons OP1 and OP2 clearly feminized the abdomen and had a slight effect on the sex combs (Table 5). No significant effect on the genitalia could be detected because most of the control, as well as the OP1 and OP2 progeny, had female genitalia. A decrease in runt dose $\left.\left(r^{L B 5}\right)^{L B}\right)$ masculinized the abdomen and the genitalia compared with the control progeny (Table 5). Neither the presence of OP1 nor run ${ }^{L B 5}$ reduced the viability of triploid intersexes, indicating that the shifts in sexual phenotype caused by OP1 and $r u n^{L B 5}$ are the result of sexual transformations and not of selective pressure. Triploid intersex progeny carrying the OP2 transposon potentially have reduced viability, but progeny with feminized abdomens and lacking sex combs like those observed in OP2 progeny were never observed in control progeny. This and the results with OP1 and run ${ }^{L B 5}$ suggest that the shift in sexual phenotype caused by OP2 is also the result of sexual transformations and not selective pressure. These results strongly suggest that runt acts as a numerator element in this assay.

Numerator elements also possess a limited ability to compensate for each other (Cline 1988; Torres and Sanchez 1989; Erickson and Cline 1991). A reduction in activity of $s i s-b$ can be overcome somewhat by a concomitant increase in the activity of sis- $a$. Females transheterozygous for $s i s-b$ and $S x l$ have reduced viability, which can be partially suppressed by an increase in sis-a activity. We tested the runt transposon OP1 for the ability to suppress the reduced viability of $s c^{3-1}, S x f^{f * 1}$ (sis$\left.b^{-}, S_{x} l^{-}\right)$trans-heterozygotes at $25^{\circ} \mathrm{C}$ and $\mathrm{Df}(1) 260-1$, $S_{x l^{f * 1}}\left(s i s-b^{-}, S_{x} l^{-}\right)$trans-heterozygotes. In both crosses the runt OP1 transposon gave a three- to fivefold increase in the viability of these females (Table 6). This suggests that an increase in runt activity can provide some compensation for the loss of sis-b activity. Taken together, our genetic results indicate that runt acts as a numerator element in the signaling of the $\mathrm{X}$ : A ratio. We have not tested increases in runt dose for male lethality. It has been shown that increases in runt dose cause segmentation defects that are likely to be lethal. This complicates the issue because increases in runt activity could be male lethal as a result of segmentation defects or ectopic activation of $S x l$.

\section{runt activity is necessary for the appropriate regulation of $\mathrm{Sxl}$}

Our results strongly suggest that the combined reduction of runt and sis-b (T4) activity leads to a decrease in female viability because of a failure to activate $S x l$ expression. To confirm this at the molecular level we examined the expression of $S x l$ protein in female embryos trans-heterozygous for runt and sis- $b$. The cross used to generate these females generated two classes of females: trans-heterozygotes for runt and sis-b, and heterozygotes for runt. Thus, including males (which do not express Sxl) the trans-heterozygous runt, sis- $b$ females will be 
Table 5. Effects of altered runt dosage on triploid intersexes

\begin{tabular}{|c|c|c|c|c|c|c|c|c|c|}
\hline \multirow{2}{*}{$\begin{array}{l}\text { runt dosage } \\
\text { in progeny }\end{array}$} & \multicolumn{3}{|c|}{ Number of legs with sex combs } & \multicolumn{3}{|c|}{ Sex of abdomen } & \multicolumn{3}{|c|}{ Sex of genitalia } \\
\hline & 2 & 1 & 0 & male & intersex & female & male & intersex & female \\
\hline$+1+$ & 24 & 0 & 0 & 21 & 3 & 0 & 1 & 6 & 17 \\
\hline$+/+; \mathrm{OP} 1$ & 12 & 2 & 4 & 2 & 3 & 13 & 0 & 2 & 16 \\
\hline$+1+$ & 37 & 0 & 0 & 32 & 5 & 0 & 3 & 6 & 28 \\
\hline$+1+; \mathrm{OP} 2$ & 18 & 0 & 2 & 6 & 5 & 9 & 4 & 0 & 16 \\
\hline$+1+$ & 10 & 0 & 0 & 5 & 4 & 1 & 3 & 1 & 6 \\
\hline $\operatorname{run}^{L B 5} /+$ & 8 & 0 & 0 & 8 & 0 & 0 & 6 & 2 & 0 \\
\hline
\end{tabular}

Triploid intersexes with increased (OP1 and OP2) or decreased $\left(r u n^{L B 5}\right)$ runt activity were scored for sexual alterations of sex combs, abdomens, and genitalia. In each cross, siblings with unaltered runt activity $(+1+)$ provide an internal control. The number in each column indicates the number of progeny scored with that particular sexual characteristic.

$25 \%$ of the total embryos. Approximately $25 \%$ of the embryos from this cross displayed a striking pattern of Sxl expression $(55 / 231=24 \%)$. In the central region of such embryos $S x l$ expression was either dramatically reduced or absent (Fig. 1C,D). Instead of the wild-type pattern of uniform expression (Fig. 1A,B), normal levels of Sxl were only evident in the anterior and posterior regions of these embryos. This phenotype was observed as early as $S x l$ expression was detected and was maintained throughout embryogenesis (Fig. 1C,D). On the basis of the number and phenotype of these embryos, as well as all our genetic evidence, we conclude that these embryos are runt, sis-b trans-heterozygotes. In this cross the remaining females (heterozygous for runt only) also showed weak alterations in the pattern of $S x l$ expression, indicating that a runt has a slight dominant effect. A cross in which heterozygous sis- $b$ embryos were generated indicated that sis-b also has a dominant effect. However, the dominant effects of runt and sis-b were not as strong or as penetrant as those seen in the trans-heterozygous embryos. These results provide molecular evidence confirming the genetic results and supporting our model for the lethality of runt, sis-b trans-heterozygous females.

A further prediction from the slight dominant effect of runt is that the expression of $S x 1$ may be severely affected in the total absence of runt activity. Two runt null alleles [a deletion and an ethylmethane sulfonate (EMS)induced mutation] were tested, and both altered the expression of $S x l$ in the same fashion as the runt, sis-b trans-heterozygotes. Sxl expression was reduced dramatically or was absent in the central region of the embryo but remained wild type at the anterior and posterior ends (Fig. $1 \mathrm{E}, \mathrm{F}$ ). This indicates that runt activity is necessary for the normal activation of $S x 1$ expression throughout the central region of the embryo. The reduction/absence of $S x l$ expression in the central region in run ${ }^{-}$embryos would be maintained through the failure to activate the positive autoregulatory loop of $S x l$. The expression of $S x l$ at the anterior and posterior ends in run ${ }^{-}$embryos would be able to activate the positive autoregulatory loop and maintain expression in these regions.

runt expression at the time of $S x l$ activation is both temporally and spatially dynamic (Gergen and Butler 1988; M. Klingler et al., in prep.). runt is initially expressed in a broad central domain. This domain rapidly deteriorates and is replaced by a series of seven stripes of strong expression. These stripes are critical for the role of runt in segmentation, which has been shown to be dosage compensated (Gergen 1987). Because the effect on

Table 6. Effect of increased runt activity on sis-b: Sxl interaction

\begin{tabular}{|c|c|c|c|c|}
\hline \multirow[b]{2}{*}{ Maternal genotype } & \multicolumn{4}{|c|}{ Classes of progeny $y^{a}$} \\
\hline & $\frac{s i s-b^{-}}{S x I^{f \# 1}}$ & $\frac{s i s-b^{-}}{S x l^{f 1}} ;$ OP1 & $\frac{+}{S x 1^{f \# 1}}$ & $\frac{+}{S x l^{f \# 1}} ; O P 1$ \\
\hline $\begin{array}{r}\text { Df } 260-1 /+^{\mathrm{b}} \\
\left(\text { sis }-b^{-} /+\right)\end{array}$ & 4 & 19 & $(88)^{c}$ & $(88)^{\mathfrak{c}}$ \\
\hline $\begin{array}{l}s c^{3-1} /+ \\
\quad\left(s i s-b^{-} /+\right)\left(25^{\circ} \mathrm{C}\right)\end{array}$ & 22 & 75 & 96 & 96 \\
\hline
\end{tabular}

The numbers in each column indicate the number of female progeny scored in that class. For each cross females of the indicated maternal genotype were mated to males of the following genotype: $S x I^{f * 1} / \mathrm{Y} ; \mathrm{OP} 1 /+$.

$\mathrm{b}(+)$ The FM7z balancer chromosome.

'In this cross the presence of the OP1 transposon could not be scored in the female progeny heterozygous for the FM7z balancer and the $S x f^{f \# 1}$ chromosome. The total number of these females was 176 . This number was divided by two because the transposon does not appear to have any adverse effects on the viability of females (see second cross). 

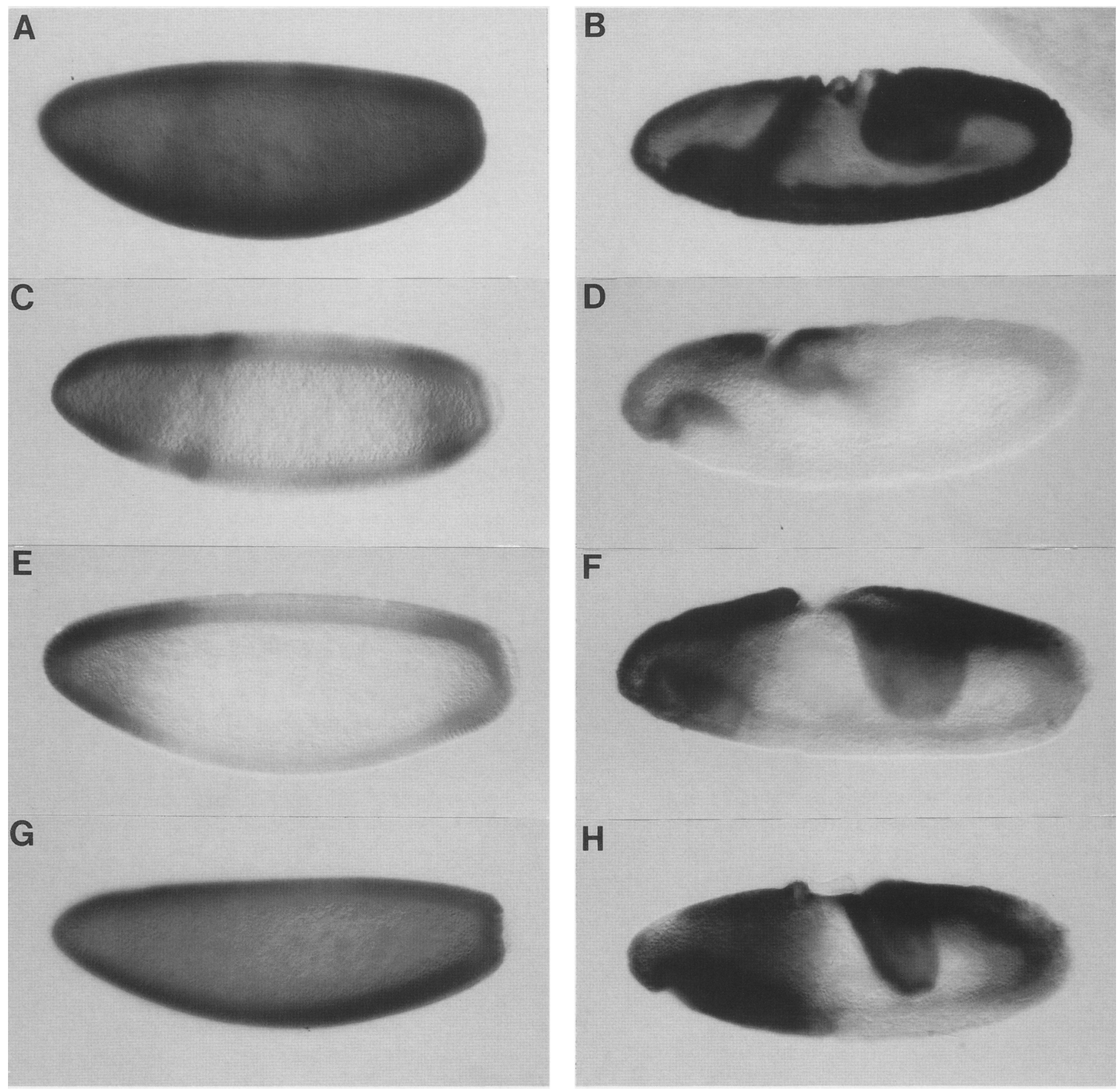

Figure 1. Alterations in $S x l$ expression. Photomicrographs of Drosophila embryos stained with anti-Sxl antibody are shown. Immunoreactivity is indicated by the brown staining reaction. All embryos are oriented with anterior to the left and dorsal up. (A) Wild-type embryo during the cellular blastoderm stage showing the normal expression of $S x l$. Gradations in the expression can be seen dorsally and mid-laterally. $(B)$ Wild-type embryo during gastrulation showing the normal pattern of $S x I$ expression. $(C, D) s c^{3-1}$, run ${ }^{L B 5}$ trans- $^{-}$ heterozygous embryos during cellular blastoderm and germ-band extension, respectively. The expression of $S x l$ is reduced severely and sometimes absent in the central region of these embyros. $(E, F)$ Homozygous run ${ }^{L B 5}$ embryos during cellular blastoderm and germ-band extension, respectively. Again, the expression of $S x l$ is reduced severely and sometimes absent from the central region of these embryos. The pole cells, which do not express $S x l$ at this stage, are evident in $E$ and provide an internal control as to the level of background staining. There is no staining of the pole cells, indicating that the low levels of expression evident in the central region are real. $(G)$ run $^{-}$; tor ${ }^{g f}$ embryo during the cellular blastoderm stage. The reduction of $S x l$ expression caused by the absence of runt has been suppressed by the tor ${ }^{g f}$ allele causing uniform $S x l$ expression. $(H)$ run ${ }^{-} ; 4 \times b c d$ embryo during germ-band extension. The anterior expression of $S_{x} l$ has expanded posteriorly causing the central domain lacking expression to shrink.

Sxl expression is not a striped or reiterated effect and the later striped expression of runt is dosage compensated, we believe that the early broad central domain and not the seven stripes of runt expression is necessary for $S x 1$ activation.

To determine whether the expression of $S x l$ was being 
affected solely by an alteration in positional information, Sxl expression was analyzed in embryos homozygous for other segmentation mutants. The Krüppel $(K r)$ gene provides positional information necessary for the formation of the central region of the embryo. If $S x l$ expression is affected by a lack of positional information in this region, then $S \times l$ expression should be affected in $\mathrm{Kr}^{-}$. However, no alteration in the expression of $S x l$ was observed in $\mathrm{Kr}^{-}$, knirps $^{-}\left(\mathrm{kni}^{-}\right)$, or hunchback ${ }^{-}\left(\mathrm{hb}^{-}\right)$. This suggests that the expression of $S x l$ expression is not disrupted solely by alterations in positional information.

\section{Sxl regulation is influenced by the maternal anterior and terminal systems}

In female embryos the transcription of $S x l$ is activated in all somatic cells to promote proper sexual development and dosage compensation. The demonstration that runt is involved in activating $S x l$ only in the central region of the embryo proves that the activation of $S x l$ requires nonuniform inputs. Similar regional effects on the activation of $S x l$ have been documented with mutations that reduce sis-b and $d a$ activity (Bopp et al. 1991). However, unlike runt, further reduction in the activity of these genes leads to a failure to activate $S x l$ in all regions of the embryo. This suggests that although the central region is more sensitive to a loss of these particular gene products, $s i s-b$ and $d a$ are required in all regions of the embryo to activate $S x l$. Our results indicate that runt cooperates with $s i s-b$ to activate $S x l$ in the central region of the embryo. These results suggest that with respect to SxI activation there are genes besides runt necessary for distinguishing the anterior and posterior regions of the embryo from the central region. The absence of any effects on $\mathrm{Sxl}$ expression by gap gene mutations $\left(\mathrm{Kr}^{-}, \mathrm{kni}^{-}\right.$, $h b^{-}$/ suggests that these hypothetical genes do not require gap gene input to provide their positional information to Sxl. Do these hypothetical genes respond to the maternal anterior and terminal organizing systems?

We investigated this possibility by altering the embryonic fate map with extra copies of the maternal anterior morphogen bicoid (bcd) or with a gain-of-function (gf) allele of the maternal terminal gene torso (tor). The $b c d$ protein forms a concentration gradient responsible for determining the anterior half of the embryonic fate map (for review, see Klingler 1990). Any change in this gradient results in a concomitant change in the fate map. In embryos with four doses of maternal $b c d$ the anterior fate map is expanded (Driever and Nüsslein-Volhard 1988). In female embryos with four doses of maternal $b c d$ and lacking runt activity the anterior domain of $S x l$ expression expands posteriorly causing the central domain that lacks $S x l$ expression to shrink (Fig. 1H). This shift indicates that $b c d$ is involved in the pathway that leads to the activation of $S x l$ in the anterior region.

The tor gene is involved in the determination of the terminal regions of the embryonic fate map (for review, see Klingler 1990). tor loss-of-function mutations result in the absence of embryonic termini and the expansion of the remaining fate map. In contrast, tor gain-of-function $\left(\right.$ tor $^{g f} \mid$ mutations result in the expansion of the embryonic termini at the expense of the segmented body region. In tor ${ }^{g f}$ embryos the expression of segmentation genes is dramatically reduced or eliminated (Klingler et al. 1988). In $t^{g f}{ }^{g f}$ female embryos $S x l$ expression is uniform, irrespective of runt activity (Fig. 1G). Thus, increased tor activity compensates for the absence of runt activity to activate $S \times l$ in the central region. This suggests that tor is also involved in the pathway that leads to the activation of $S \times l$ in the terminal regions.

It is important to note that any shift in the pattern of Sxl in the $4 \times b c d$ or $t^{g}{ }^{g f}$ embryos is not the result of a shift in the runt domain, because these effects were scored in embryos lacking runt activity. Therefore, any shift in $S x l$ expression must be the result of $b c d$ and tor or their effects on a gene(s) other than runt.

\section{Discussion}

Our genetic and molecular characterization of a vital interaction between the segmentation gene runt and the numerator element $s i s-b$ has led to the discovery that runt is part of the signal that acts to regulate $S x l$. An independent screen for genes that interact with $S x l$ has also indicated that runt is involved in this process $(M$. Torres and L. Sanchez, pers. comm.). The transduction of the $\mathrm{X}$ : A ratio to $S \times 1$ appears to require three classes of genes: (1) X : A elements (sis genes); (2) X : A transduction genes $(d a)$; and $(3)$ the $\mathrm{X}: \mathrm{A}$ target gene $(\mathrm{Sx})$ (Cline 1988). Our results indicate that runt is not just involved with this process ( $\mathrm{X}: \mathrm{A}$ transduction gene) but is part of the signal ( $\mathrm{X}: \mathrm{A}$ numerator element). runt is $\mathrm{X}$-linked and has zygotic dose-dependent interactions with other components of this process, increases and decreases in runt activity alter the sexual phenotype of triploid intersexes, runt can partially compensate for a reduction in $s i s-b$ activity, and runt is necessary for the appropriate expression of $S x l$. On the basis of these results we conclude that runt acts as an $\mathrm{X}: \mathrm{A}$ numerator element.

By definition, the role of runt as a numerator element should not be dosage compensated because it functions in the initiation of $S x l$ expression, whose activity then regulates dosage compensation. In this light it is interesting to reconsider the demonstration that the later role of runt in formation of the body pattern is dosage compensated (Gergen 1987). This conclusion was based on the sex-specific effects of a $S x l$ null allele on the segmentation phenotype of a hypomorphic runt allele $\left(\right.$ run $\left.^{\text {YC28 }}\right)$. Sxl expression is reduced to intermediate levels in homozygous female run ${ }^{\mathrm{YC} 28}$ embryos, and females transheterozygous for run ${ }^{Y C 28}$ and sis-b mutations have reduced viability (J.B. Duffy, unpubl.). These observations suggest that the intermediate levels of $S_{x l}$ activity present in female run ${ }^{Y C 28}$ embryos are sufficient for controlling the dosage compensation of runt during segmentation, indicating that the on state of $S x l$ in wild-type female embryos is at higher levels than are required for this function. This raises the possibility that high levels 
are generated in wild-type females to satisfy the need for other functions of Sxl.

A surprising finding is that the activity of runt as a numerator element is required only in the central region of female embryos. This result and the demonstration that $S x l$ expression is regulated by the maternal anterior and terminal systems indicates that the uniform /occurs in all somatic cells) expression of $S x l$ in females requires nonuniform inputs. Although the embryonic promoter of $S x l$ is activated in all female somatic cells, gradations in the initial expression of $S \mathrm{x} l$ can be seen in wild-type female embryos (Fig. 1A). These differences in the levels of $S x 1$ expression are consistent with nonuniform inputs and presumably reflect the sensitivity of the $S x l$ promoter to such inputs (like runt).

Our results have a number of important implications regarding the transduction of the $\mathrm{X}$ : A signal. First, the discovery that runt acts as a numerator element only in the central region of the embryo demonstrates there are nonuniform inputs into $S x l$ activation. Although sis- $b$ acts to regulate $S x l$ throughout the embryo, runt only has such effects in the central region of the embryo. This indicates that all numerator elements may not have similar effects on Sxl activation. For example, runt and sis-b are both required in the central region, and the reduction of the dose of both results in a failure to activate $S \times 1$. However, if two genes are required in different regions of the embryo (anterior vs. central) they may fail to interact with each other. In addition, genes required only in regions where sexually dimorphic markers are not available may not be detected using triploid intersexes as an assay. This suggests that the ability of a gene to act as a numerator element may vary with the assay, which could result in the appearance of conflicting results. Second, the role of runt in other developmental pathways hindered the discovery of its role in sex determination/ dose compensation. Other genes involved in $S x l$ activation may also have additional developmental roles that could hinder the discovery of their role in sex determination/dosage compensation.

Third, the involvement of runt in sex determination/ dosage compensation demonstrates that not all regulators of $S x l$ are members of the bHLH family of transcription factors. The runt gene encodes a nuclear protein that does not contain previously characterized DNAbinding or dimerization motifs (Kania et al. 1990). The sequence of runt encodes a putative ATP-binding domain but does not encode other motifs indicative of a kinase. Although the role of runt in regulating the expression of other genes has been documented, its biochemical function remains elusive. One intriguing possibility is that the function of runt involves modulating the dimerization or DNA-binding activity of transcription factors. Consistent with this is the following observation on the roles of $s i s-b, d a$, and runt in regulating the expression of $S x l$ : Low levels of $S x l$ expression can occur in the absence of runt activity (Fig. 1E,F), indicating that runt is not absolutely required for the transcriptional initiation of $S x l$. This contrasts with the complete elimination of $S \times l$ expression in the absence of $s i s-b$ or $d a$ activity. These observations suggest that the role of runt as a numerator element involves amplifying the ability of other numerator elements to activate $S x l$ expression.

Finally, the observation that $S x l$ regulation is influenced by $b c d$ and tor provides additional evidence for nonuniform inputs. The complete restoration of $S x 1$ expression in run ${ }^{-}$embryos by tor $^{g f}$ provides a particularly striking example of this. Because tor is a putative transmembrane tyrosine kinase, its effect on $S x l$ is likely to be indirect. This predicts the existence of another gene capable of mediating the positive effects of tor on Sxl. These effects (as well as those of $b c d$ ) could be mediated by positive activators, such as sis-a, sis-b, and $d a$ or through a novel activator. One potential candidate for such a novel activator was the segmentation gene giant $(g t) . g t$ is a zygotic X-linked gene expressed in an anterior and posterior domain at the time of $S x l$ activation (Mohler et al. 1989; Eldon and Pirrota 1991; Kraut and Levine 1991). Thus, $g t$ is capable of providing positional information in the regions where runt does not. However, the absence of gt activity has no effect on the expression of Sxl (J.B. Duffy, unpubl.).

A second possibility is that the positive effects of tor and $b c d$ are achieved through the repression of an inhibitor of $S x l$ activation in the central region (denominator element). The effects of $4 \times b c d$ and $t^{g f}$ on the expression of this inhibitor should be complementary to their effects on $S x l$ expression. For example, in $t o r^{g f}$ embryos the expression of this inhibitor would be repressed. This repression would eliminate the need for runt in the central region and explain why $S x l$ expression is uniform in the absence of runt activity. Any effect on $S_{x} l$ activation due to a reduction in the activity of runt should be restored by a concomitant reduction in the activity of this inhibitor(s). Several lines of evidence suggest that the segmentation gene $h$ could be such an inhibitor. The $h$ gene encodes a protein of the bHLH family, and its misexpression has been shown to interfere with the ability of $s i s-b$ to activate $S x l$. Furthermore, the complementary expression and approximately reciprocal effects of $h$ and runt during segmentation suggests mutual antagonism (Ingham and Gergen 1988; Kania et al. 1990). However, preliminary results suggest that the issue is more complicated than this simple model. Although the reduction in viability of females trans-heterozygous for runt and $s i s-b$ is rescued by a mutation in $h$, homozygosity for a mutation in $h$ does not result in the ectopic expression of $S x l$ in males (J.B. Duffy, unpubl.).

We have shown that the segmentation gene runt functions as a numerator element that provides nonuniform input necessary for the appropriate regulation of $S x l$. It is interesting to speculate that the regulation of $S x l$ has evolved to utilize the levels of gene products that function in other developmental pathways. For example sis$b$, da (for review, see Ghysen and Dambly-Chaudiere 1988; Cline 1989), and runt (Duffy et al. 1991) all function during neurogenesis. We propose that the assessment of the X : A ratio and activation of $S x l$ involve both positive and negative input from additional genes with other developmental roles and that (as with runt) such 
dose-sensitive regulatory information may be provided to the $S x l$ promoter in a nonuniform manner. By coopting other developmentally important gene products to generate its uniform pattern of expression the $S \times l$ promoter appears to have evolved a more complicated mechanism of regulation than the simple mechanisms that one might have predicted.

\section{Materials and methods}

Drosophila stocks

All runt alleles used in this paper are described in Gergen and Weischaus (1986). The runt transposons OP1 and OP2 are described in Gergen and Butler (1988). The T4 transposon, $S_{x} I^{f \# 1}$, $S x l^{M \# 1}$, Df(1)N71, and the $y w ; \mathrm{C}(2 \mathrm{~L}) \mathrm{RM}, d p ; \mathrm{C}(2 \mathrm{R}) \mathrm{RM}, p x$; $\mathrm{C}\left(3 \mathrm{~L} / \mathrm{R} M, h^{2, r s^{2}}, \mathrm{C}(3 \mathrm{R})\right.$, + stocks were provided by T. Cline and J. Erickson. The In $(1) y^{3 p l}-s c^{8 r}$ and $\operatorname{In}(1) s c^{81}-s c^{4 r}$ were provided by C. Cabrera and C. Dambly-Chaudiere. Df(1) sc ${ }^{2}$ was provided by the Jan laboratory. A strain with two copies of a bcd transposon was obtained from R. Finkelstein and N. Perrimon. All other stocks were obtained from the Indiana Stock Center. All stocks and crosses were maintained at $25^{\circ} \mathrm{C}$ (unless otherwise noted) in uncrowded conditions on standard cornmeal/agar medium.

\section{Genetics}

For all crosses where a wild-type chromosome is indicated $(+)$ this represents a chromosome obtained by outcross to a stock homozygous for an X chromosome carrying the $y$ and $w^{67 c 23}$ mutations and no second- or third-chromosome mutations.

For Table 1 the deficiency or point mutation chromosomes were followed in the progeny by the closely linked genes yellow and white. Their genotypes with respect to these markers are $\operatorname{Df}(1) 260-1, y^{-} \quad w^{+} ; \operatorname{Df}(1) s c^{19}, y^{-} w^{+} ; \operatorname{Df}(1) s c^{2}, y^{+} w^{+}$; $\operatorname{In}(1) y^{3 P L}-s c^{8 R}, y^{-} w^{+} ; \operatorname{In}(1) s c^{8 L}-s c^{4 R}, y^{+} w^{+} ; y^{+} s c^{10-1} w^{+}$;

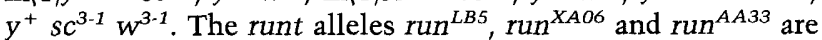
all marked with $y^{-}$and $w^{-}$.

The $\mathrm{D}(1) s c^{19}$, run ${ }^{L B 5}$ recombinants in Table 2 were generated by mating females trans-heterozygous $\mathrm{Df}(1) s c^{19}$ and run ${ }^{L B 5}$ to FM7 males. Single, virgin female progeny with a potential recombinant chromosome balanced over FM7 were mated again to FM7 males to establish a stock. After one generation each stock was tested for the presence of $D f(1) s c^{19}$ and $\operatorname{run}^{L B 5}$ by separately mating to males carrying a Y-chromosome duplication for the $A S-C$ and to males carrying a Y-chromosome duplication for runt and scoring the progeny. At the same time, to determine whether $\mathrm{T} 4$ and runt interacted in a cis-heterozygous configuration these stocks were also crossed to yw males to score the viability of the recombinants before modifiers could accumulate. Subsequently, whenever testing the recombinant lines for rescue by transposons they also tested with yw males as a control to determine whether modifiers had accumulated. The recombinant lines were mated to males homozygous for either run ${ }^{O P 1}$, run ${ }^{O P 2}$, run ${ }^{C D 2}$, or run ${ }^{L a c}$. The recombinant lines were also mated to males carrying the $\mathrm{Dp}(1: 2) s c^{19}$ balanced over SM5 and males carrying the T4 transposon balanced over CyO. The run ${ }^{L B 5} / \mathrm{FM} 7$ females were not from a recombinant line and were obtained from our stock collection.

For the analysis of bristle defects, we scored from 37-64 females trans-heterozygous for $s c^{10-1}$ and run ${ }^{L B 5}$; for Df(l)sc $c^{19}$ and $\operatorname{run}^{L B 5}$; for $s c^{10-1}$ and $y w$; and for $\mathrm{Df}(1) s c^{19}$ and $y w$. Females of these genotypes were scored for the presence/absence of the following bristles: scutellars, orbitals, ocellar, verticals, post- vertical, humerals, presutural, notopleurals, supra-alars, postalars, and dorsocentrals.

The Df( 1$) s c^{19}, S x I^{M \# 1}$ recombinants in Table 3 were generated by mating females trans-heterozygous $\mathrm{Df}(1) s c^{19}$ and $S x l^{M \# 1}$ to FM7 males. Single, virgin female progeny with a potential recombinant chromosome balanced over FM7 were mated again to FM7 males to establish a stock. Each stock was tested for the presence of $\mathrm{Df}(1) s c^{19}$ and $S \times I^{M \# 1}$ by mating to males carrying the $\mathrm{Df}(1) s c^{19}$ and Y-chromosome duplication for the $A S-C$. These stocks were then tested for the ability to suppress the runt-T4 interaction.

The triploid intersexes in Table 5 were created by mating females heterozygous for either run ${ }^{O P 1}$, run ${ }^{O P 2}$, or run ${ }^{L B 5}$ to males of the genotype $y w ; C(2 L) R M, d p ; C(2 R) R M, p x$; $\mathrm{C}(3 \mathrm{~L}) \mathrm{RM}, h^{2}, r s^{2} ; \mathrm{C}(3 \mathrm{R}),+$. Because balancer chromosomes have multiple mutations and triploid intersexes are sensitized to genetic background, the run ${ }^{O P 1}$, run ${ }^{O P 2}$, and run $^{L B 5}$ females were made heterozygous with nonbalancer chromosomes to reduce possible background effects. This also allows for free recombination further reducing the possibility of effects due to genetic background. We were able to follow the run ${ }^{O P 1}$, run ${ }^{O P 2}$ transposons because they are $w^{+}$and the experiment was performed in a $w^{-}$background. The $w^{-}, \operatorname{run}^{L B 5} \mathrm{X}$ chromosome was heterozygous over a $w^{-} \mathrm{X}$ chromosome that contained a non-runt $w^{+}$transposon (P298) inserted at 20D. Because run is located at $19 \mathrm{E}$, the recombination frequency between the run ${ }^{L B 5}$ allele and the non-runt $w^{+}$transposon is $<0.1 \mathrm{mU}$. Thus, $w^{+}$indicates a wild-type $\mathrm{X}$ chromosome (with respect to runt) in the triploid progeny and $w^{-}$indicates the run ${ }^{L B 5} \mathrm{X}$ chromosome in the triploid progeny. The presence of any sex comb teeth was scored as the presence of a sex comb. The sexual character of the abdomen was based on pigmentation of the abdominal tergites. Triploid intersex progeny were scored as intersexual for pigmentation when the $6 / 7$ tergite was composed entirely of male pig. mented tissue and the next most anterior tergite was composed of large patches of male and female pigmented tissue. To score the genitalia the external genitalia and analia were analyzed for male and female structures. Triploid intersex progeny were scored as intersexual when parts of both male and female structures were evident.

For Table 6 a $w^{-}$mutation was recombined onto the Df(1)260-1 and the $S x l^{f \# 1}$ chromosomes. The $s c^{3-1}$ chromosome also contained the mutation $w^{3-1}$. The $w^{-}$mutation allowed us to follow the presence of the run ${ }^{O P 1}$ transposon in these crosses.

The $4 \times$ bcd; run ${ }^{-}$embryos were generated by mating females heterozygous for run ${ }^{L B 5}$ and a chromosome carrying two copies of a $b c d \mathrm{P}$ transposon (with the two endogenous copies of $b c d$, this provides $4 \times b c d$ dosage) to run ${ }^{L B 5}$ males carrying the run ${ }^{+}$ Y-chromosome duplication $y^{+} \mathrm{Ymal}^{102}$. Half of the female embryos from this cross will be run ${ }^{-}$in addition to having received $4 \times$ bcd dosage. The tor ${ }^{8 f(4021)}$ and tor $^{\left(Y^{(9)}\right.}$; run $^{-}$embryos were generated by mating females heterozygous for $\operatorname{run}^{L B 5}$ and the tor $^{\text {gf }}$ alleles 4021 or $\mathrm{Y} 9$ to run ${ }^{L B 5}$ males carrying the run $^{+}$ Y-chromosome duplication $y^{+} \mathrm{Ymal}^{102}$. Half of the female embryos from this cross will be run ${ }^{-}$in addition to having increased tor activity. All of the female embryos derived from these crosses showed uniform staining of $S x l$, indicating that the loss of runt activity in half of these females was suppressed by the increased tor activity. The embryo in Figure 1G is a representative female from these crosses.

\section{Immunohistochemistry}

The wild-type embryos were from a stock homozygous for yellow and $w^{67 c 23}$. The $s c^{3-1}$, run ${ }^{L B 5}$ trans-heterozygous embryos were generated by mating $s c^{3-1} /+$ females to $\operatorname{run}^{L B 5} / y^{+} \mathrm{Ymal}^{102}$ 
males at $30^{\circ} \mathrm{C}$. To generate female embryos homozygous for run the following crosses were done: (1) $\operatorname{run}^{L B 5} / \mathrm{FM} 7 \times \mathrm{run}^{L B 5} /$ $\mathrm{y}^{+} \mathrm{Ymal}^{102}$; and (2) run ${ }^{V E 751} / \mathrm{FM} 7 \times \mathrm{run}^{V E 751} / \mathrm{y}^{+} \mathrm{Ymal}^{102}$. $r^{2 u n^{L B 5}}$ is a $5-\mathrm{kb}$ deletion including the runt transcription unit, and run ${ }^{V E 751}$ is a point mutation; both alleles have a null segmentation phenotype and both interact with sis-b. The $S \times 1$ antibody was a monoclonal antibody obtained from Daniel Bopp (Princeton University). The monoclonal supernatant was used at a $1: 10$ dilution for staining embryos. Immunohistochemistry of embryos was performed as described in Kania et al. (1990).

\section{Acknowledgments}

We appreciate the gift of stocks from C. Cabrera, C. DamblyChaudiere, the Jan laboratory, R. Finkelstein, N. Perrimon, T. Cline, J. Erickson, and the Indiana Stock Center. We especially thank Tom Cline and James Erickson for their insight and assistance. We thank Tom Cline and Martin Klingler for valuable comments and criticisms on the manuscript, and Miguel Torres and Lucas Sanchez for sharing unpublished data. The generous gift of $S x I$ antibody was kindly provided by Daniel Bopp and is greatly appreciated.

The publication costs of this article were defrayed in part by payment of page charges. This article must therefore be hereby marked "advertisement" in accordance with 18 USC section 1734 solely to indicate this fact.

\section{References}

Bell, L.R., E.M. Maine, P. Schedl, and T.W. Cline. 1988. Sexlethal, a Drosophila sex determination switch gene, exhibits sex-specific RNA splicing and sequence similarity to RNA binding proteins. Cell 55: 1037-1046.

Bell, L.R., J.I. Horabin, P. Schedl, and T.W. Cline. 1991. Positive autoregulation of Sex-lethal by alternative splicing maintains the female determined state in Drosophila. Cell 65: 229-239.

Bopp, D., L.R. Bell, T.W. Cline, and P. Schedl. 1991. Developmental distribution of female-specific Sex-lethal proteins in Drosophila melanogaster. Genes \& Dev. 5: 403-415.

Botas, J., J. Moscoso del Prado, and A. Garcia-Bellido. 1982. Gene dose titration analysis in the search of trans-regulatory genes in Drosophila. EMBO J. 1: 307-310.

Bridges, C.B. 1921. Triploid intersexes in Drosophila melanogaster. Science 54: 252-254

1925. Sex in relation to chromosomes and genes. Am. Nat. 59: 127-137.

Caudy, M., H. Vaessin, M. Brand, R. Tuma, L.Y. Jan, and Y.N. Jan. 1988. daughterless, a Drosophila gene essential for both neurogenesis and sex determination, has sequence similarities to myc and the achaete-scute complex. Cell 55: 10611067.

Cline, T.W. 1978. Two closely linked mutations in Drosophila melanogaster that are lethal to opposite sexes and interact with daughterless. Genetics 90: 683-698.

- 1983. The interaction between daughterless and Sexlethal in triploids: A lethal sex-transforming maternal effect linking sex determination and dosage compensation in Drosophila melanogaster. Dev. Biol. 95: 260-274.

- 1984. Autoregulatory functioning of a Drosophila gene product that establishes and maintains the sexually determined state. Genetics 107: 231-277.

- 1986. A female-specific lethal lesion in an X-linked positive regulator of the Drosophila sex determination gene, Sex-lethal. Genetics 113: 641-663.
1988. Evidence that sisterless- $a$ and sisterless- $b$ are two of several discrete "numerator elements" of the X/A sex determination signal in Drosophila that switch $S x l$ between two alternative stable expression states. Genetics 119: 829862.

- 1989. The affairs of daughterless and the promiscuity of developmental regulators. Cell 59: 231-234.

Cronmiller, C., P. Schedl, and T.W. Cline. 1988. Molecular characterization of daughterless, a Drosophila sex determination gene with multiple roles in development. Genes \& Dev. 2: 1666-1676.

Cubas, P., J.F. de Celis, S. Campuzano, and J. Modelell. 1991. Proneural clusters of achaete-scute expression and the generation of sensory organs in the Drosophila imaginal wing disc. Genes \& Dev. 5: 996-1008.

Dambly-Chaudiere, C., A. Ghysen, L.Y. Jan, and Y.N. Jan. 1988. The determination of sense organs in Drosophila: Interactions of scute with daughterless. Wilhelm Roux's Arch. Dev. Biol. 197:419-423.

Driever, W. and C. Nüsslein-Volhard. 1988. The bicoid protein determines position in the Drosophila embryo in a concentration-dependent manner. Cell 54: 95-104.

Duffy, J.B., M.A. Kania, and J.P. Gergen. 1991. Expression and function of the Drosophila gene runt in early stages of neural development. Development (in press).

Eldon, E.D. and V. Pirrota. 1991. Interactions of the Drosophila gap gene giant with maternal and zygotic pattern-forming genes. Development 111: 367-378.

Ellis, H.M., D.R. Spann, and J.W. Posakony. 1990. extramacrochaetae, a negative regulator of sensory organ development in Drosophila, defines a new class of helix-loop-helix proteins. Cell 61: 27-38.

Erickson, J. and T.W. Cline. 1991. The molecular nature of the Drosophila sex determination signal and its link to neurogenesis. Science 251: 1071-1074.

Garcia-Alonso, L.A. and A. Garcia-Bellido. 1988. extramacrochaetae, a trans-acting gene of the achaete-scute complex of Drosophila involved in cell communication. Wilhelm Roux's Arch. Dev. Biol. 197: 328-338.

Garrell, J. and J. Modolell. 1990. The Drosophila extramacrochaetae locus, an antagonist of proneural genes that, like these genes, encodes a helix-loop-helix protein. Cell 61: 3948.

Gergen, J.P. 1987. Dosage compensation in Drosophila: Evidence that daughterless and Sex-lethal control X chromosome activity at the blastoderm stage of embryogenesis. Genetics 117: 477-485

Gergen, I.P. and E. Weischaus. 1986. Dosage requirements for runt in the segmentation of Drosophila embryos. Cell 45: 289-299.

Gergen, J.P. and B.A. Butler. 1988. Isolation of the Drosophila segmentation gene runt and analysis of its expression during embryogenesis. Genes \& Dev. 2: 1179-1193.

Ghysen, A. and C. Dambly-Chaudiere. 1988. From DNA to form: The achaete-scute complex. Genes \& Dev. 2: 495501.

Ingham, P.W. and J.P. Gergen. 1988. Interactions between the pair-rule genes runt, hairy, even-skipped and fushi tarazu and the establishment of pattern in the Drosophila embryo. Development 104 (suppl.): 51-60.

Ingham, P.W., K.R. Howard, and D. Ish-Horowicz. 1985. Transcription pattern of the Drosophila segmentation gene hairy. Nature 318: 439-445.

Kania, M.A., A.S. Bonner, J.B. Duffy, and J.P. Gergen. 1990. The Drosophila segmentation gene runt encodes a novel nuclear regulatory protein that is also expressed in the developing 
nervous system. Genes \& Dev. 4:1701-1713.

Klingler, M. 1990. The organization of the antero-posterior axis. Sem.Cell Biol. 1: 151-160.

Klingler, M., M. Erdelyi, J. Szabad, and C. Nüsslein-Volhard. 1988. Function of torso in determining the terminal anlagen of the Drosophila embryo. Nature 335: 275-277.

Kraut, R. and M. Levine. 1991. Spatial regulation of the gap gene giant during Drosophila development. Development 111: 601-609.

Lucchesi, J. C. and T. Skripksy. 1981. The link between dosage compensation and sex differentiation in Drosophila melanogaster. Chromosoma 82: 217-227.

Maine, E.M., H.K. Salz, P. Schedl, and T.W. Cline. 1985. Sexlethal, a link between sex determination and sexual differentiation in Drosophila melanogaster. Cold Spring Harbor Symp. Quant. Biol. 50: 596-604.

Mohler, J., E.D. Eldon, and V. Pirrota. 1989. A novel spatial transcription pattern associated with the segmentation gene, giant, of Drosophila. EMBO I. 8: 1539-1548.

Moscoso del Prado, J. and A. Garcia-Bellido. 1984a. Genetic regulation of the achaete-scute complex of Drosophila melanogaster. Wilhelm Roux's Arch. Dev. Biol. 193: 242-245.

- 1984b. Cell interactions in the generation of chaetae pattern in Drosophila. Wilhelm Roux's Arch. Dev. Biol. 193: 246-251.

Murre, C., P.S. McCaw, and D. Baltimore. 1989a. A new DNA binding and dimerization motif in immunoglobulin enhancer binding, daughterless, $M y o D$, and myc proteins. Cell 56: $777-783$.

Murre, C., P.S. Mccaw, H. Vaessin, M. Caudy, L.Y. Jan, Y.N. Jan, C. Cabrera, J.N. Buskin, S.D. Hauschka, A.B. Lassar, H. Weintraub, and D. Baltimore. 1989b. Interactions between heterologous helix-loop-helix proteins generate complexes that bind specifically to a common DNA sequence. Cell 58: $537-544$.

Parkhurst, S.M., D. Bopp, and D. Ish-Horowicz. 1990. X : A ratio, the primary sex-determining signal in Drosophila, is transduced by helix-loop-helix proteins. Cell 63:1179-1191.

Rushlow, C.A., A. Hogan, S.M. Pinchin, K.M. Howe, M. Lardelli, and D. Ish-Horowicz. 1989. The Drosophila hairy protein acts both in segmentation and bristle patterning and shows homology to N-myc. EMBO J. 8: 3095-3103.

Salz, H.K., E.M. Maine, L.N. Keyes, M.E. Samuels, T.W. Cline, and P. Schedl. 1989. The Drosophila female-specific sex-determination gene, Sex-lethal, has stage-, tissue-, and sex-specific RNAs suggesting multiple modes of regulation. Genes \& Dev. 3: 708-719.

Sanchez, L. and R. Nothiger. 1983. Sex determination and dosage compensation in Drosophila melanogaster: Production of male clones in XX females. EMBO I. 2: 485-491.

Skeath, J. and S. Carroll. 1991. Regulation of achaete-scute gene expression and sensory organ pattern formation in the Drosophila wing. Genes \& Dev. 5: 984-995.

Steinmann-Zwicky, M., H. Amrein, and R. Nothiger. 1990. Genetic regulatory hierarchy in development: Genetic control of sex determination in Drosophila. Adv. Genet. 27:189237.

Torres, M. and L. Sanchez. 1989. The scute (T4) gene acts as a numerator element of the $\mathrm{X}$ : A signal that determines the state of activity of Sex-lethal in Drosophila. EMBO $J$. 8: 3079-3086.

Villares, R. and C.V. Cabrera. 1987. The achaete-scute gene complex of D. melanogaster: Conserved domains in a subset of genes required for neurogenesis and their homology to myc. Cell 50: 415-424. 


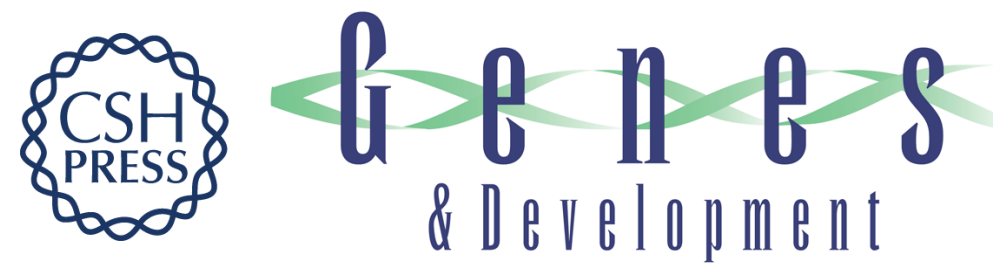

\section{The Drosophila segmentation gene runt acts as a position-specific numerator element necessary for the uniform expression of the sex-determining gene Sex-lethal.}

J B Duffy and J P Gergen

Genes Dev. 1991, 5:

Access the most recent version at doi:10.1101/gad.5.12a.2176

References This article cites 47 articles, 18 of which can be accessed free at:

http://genesdev.cshlp.org/content/5/12a/2176.full.html\#ref-list-1

License

Email Alerting Service

Receive free email alerts when new articles cite this article - sign up in the box at the top right corner of the article or click here.

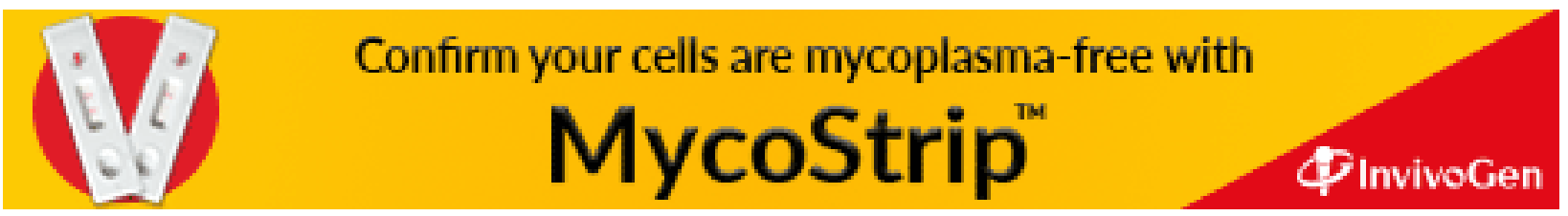

